\title{
A PROXÊMICA NO AMBIENTE EMBARCADO: ESTUDO DE CASO DE UM VELEIRO ADAPTADO PARA MORADIA
}

\section{PROXEMICS IN THE EMBEDDED ENVIRONMENT: A CASE STUDY OF A SAILBOAT ADAPTED FOR HOUSING}

\author{
Silvana Souza Silverio ${ }^{1}$, Me. \\ sils.souzas@gmail.com e https://orcid.org/0000-0002-4194-8303 \\ Debora Barauna ${ }^{2}$, Dra. \\ debora.barauna1@gmail.com e https://orcid.org/0000-0002-5841-9897 \\ Gabriela Botelho Mager ${ }^{1}$, Dra. \\ gabrielamager@gmail.com e https://orcid.org/0000-0001-6102-7344
}

\footnotetext{
${ }^{1}$ Universidade do Estado de Santa Catarina - UDESC, Florianópolis, Brasil

${ }^{2}$ Universidade do Vale do Rio dos Sinos - UNISINOS, Porto Alegre, Brasil
}

Veleiros, Design de Interiores, Proxêmica

Na busca por fatores que sejam condicionantes de bem estar, a Proxêmica apresenta um arcabouço de informações relevantes, capaz de levar a compreensão da relação do indivíduo com o espaço e com os outros nele presentes. Sendo essa uma premissa para a definição de um layout mais coerente e passível de valorização do lugar de convívio, o objetivo deste artigo é organizar, de forma sistemática, as adequações espaciais realizadas em uma embarcação a vela adaptada para moradia de um casal de indivíduos. Assim, trata-se de um estudo de caso e baseia-se na investigação do antropólogo Edward T. Hall acerca das manifestações proxêmicas. Fora utilizado o caso de um veleiro de 36 pés que, após sua reforma, será utilizado como moradia por um casal, e através da análise fundamentada nos preceitos da Proxêmica foram apresentadas adaptações que resultem em melhor interação entre os usuários e entre estes com o espaço. Essas adaptações serviram de base para a elaboração de um conjunto de características que favoreçam outros projetos semelhantes.

\section{Sailboat, Interior Design, Proxemics}

In the search for factors that are conditioning factors of well-being, the proxemic presents a framework of relevant information, capable of leading to an understanding of the individual's relationship with the space and with the others present in it. This being a premise for the definition of a more coherent layout and capable of enhancing the place of conviviality, the objective of this article is to systematically organize the spatial adaptations carried out on a sailing vessel adapted for the housing of a couple of individuals. Thus, it is a case study and is based on anthropologist Edward T. Hall's investigation of proxemic manifestations. The case of a 36-foot sailboat had been used which, after its renovation, will be used as a home by a couple, and through analysis based on the precepts of the proxemic, adaptations were presented that result in better interaction between users and between them and the space. These adaptations served as a basis for the elaboration of a list of characteristics that favor other similar projects. 


\section{Introdução}

A realidade contemporânea tem exposto novos modos viver, ser e estar no mundo. Neste complexo, o papel do design na sociedade também tem se transformado, passando a envolver, além de o desenvolvimento de produtos em escala, a concepção de novos sistemas, produtos e serviços personalizados e mais adequados ao ser humano e à complexidade das relações com o seu meio.

Assim, mediante ao fato do aumento da busca pelo nomadismo, aliado ao momento social em que os trabalhos têm se tornado mais remotos, o foco desta pesquisa observa, por meio das teorias apresentadas pelo conceito proxêmico, a falta de adequação nos layouts de embarcações a vela habitadas atualmente. Esses layouts tradicionalmente são baseados em arranjos focados para profissionais da vela ou com modos de vida distantes daqueles praticados pelos usuários de hoje do universo náutico, que buscam um local para lazer por longos períodos, até a sua habitação propriamente dita. Por conta da pandemia do COVID19, observou-se uma tendência de migração para o interior e para a praia, onde o setor náutico encerrou o ano de $2020 \mathrm{com}$ um crescimento de 30\%, segundo a Associação Náutica Brasileira (CASTRO, 2021), e muitas dessas novas embarcações foram construídas como nova forma de moradia para seus usuários.

Os veleiros, ponto focal desta pesquisa, são embarcações que além de propiciar a prática do esporte ligado à movimentação através do vento, também podem oferecer um espaço habitável, dependendo de suas dimensões. Essas dimensões podem variar, e são as características individuais do morador que acabam por definir a melhor opção para os novos habitantes daquele espaço. A partir da maior permanência, com o auxílio da Proxêmica, se pode imprimir uma orientação mais funcional, com o intuito de se compreender a relação que se estabelece entre esses habitantes em um mesmo espaço confinado - o veleiro.

A Proxêmica estuda como o ser humano organiza inconscientemente o próprio espaço a sua volta. Segundo Agnus (2012, p.1) trata-se da forma de "uso e percepção do espaço social e pessoal de alguém, como em assentos e arranjos espaciais". O autor ainda complementa:

Proxêmica pode ser definida como o estudo de meios em que os indivíduos fazem uso do espaço físico na interação entre os indivíduos. Todo e qualquer organismo do universo tenta ocupar, cultivar, preservar e utilizar o espaço. Esse processo de propriedade do espaço pelos meios acima mencionados difere de cultura para cultura. Pessoas frequentemente podem sentir-se desconfortável ao operar em espaços diferentes daqueles em que eles são familiares." (AGNUS, 2012, p.1).

Dentro das definições do antropólogo americano Edward T. Hall, a embarcação se enquadra a princípio num ambiente de características fixas. Por conta da movimentação em relação ao mar ou rio em que se encontra, os objetos não podem ser móveis, a mobília é fixa ao piso e às paredes, e há apoios para as mãos, também fixos, ao redor das áreas de passagem. Porém, como o próprio autor complementa, quando um mesmo local imóvel é utilizado para mais de uma função, este pode receber características semifixas e esse é o caso das embarcações já que, uma de suas funções naturais permanece sendo a velejada - esporte recreativo de velejar.

Dentro deste contexto, o presente artigo objetiva organizar, de forma sistemática, as adequações espaciais realizadas em uma embarcação para se tornar a habitação de um casal. A sistematização proposta baseia-se nos princípios da Proxêmica e se complementa nos fundamentos da ergonomia. Desta forma, o método adotado nesta pesquisa foi o estudo de caso de um projeto de embarcação adaptado para a moradia de dois indivíduos, enquanto casal. Sendo que, as etapas de pesquisa derivaram do entendimento prático da Proxêmica, através de um estudo exploratório, seguindo o referencial teórico de Hall (1977). Apesar de haverem autores contemporâneos que explicitam o tema, o autor supracitado permanece como fonte principal por sua completa abordagem da temática. Com isso, se partiu para as definições de briefing, medições técnicas do ambiente - dimensionamento, luminosidade, ventilação - e anotação dos detalhes projetuais que pudessem ser reconsiderados diante do estudo. A tarefa executada em cada local deve ser 
observada, já que ela pode, de acordo com a Proxêmica, provocar disparidade com os limites do corpo, e consequentemente provocar desconforto ao usuário.

A seguir, no desenvolvimento deste artigo, primeiro disserta-se sobre o comportamento espacial ou proxêmico, destacando como afirma Agnus (2012, p.2) "as três áreas fundamentais com as quais os especialistas no campo categorizam Proxêmicas", essas são: distância; espaços e modos de comportamento; e percepção. Em seguida, apresenta-se o estudo de caso e os resultados obtidos no estudo.

\section{Comportamento espacial}

Antes de tratar do comportamento espacial de indivíduos, considerando o contexto das embarcações, é importante entender como se dá a comunicação destes com as coisas, logo com os espaços. A comunicação geral se estabelece em diferentes níveis concomitantemente, variando do plenamente consciente ao inconsciente (HALL, 1977). Vasconcelos (2006) discorre que no caso da comunicação não-verbal, por vezes, é usada inconscientemente e tem forte persuasão sobre o que se pretende expressar, a ponto de modificar o que está sendo dito, isto é, contestando a comunicação verbal. Para Agnus (2012, p2) “o comportamento proxêmico torna-se um importante campo de estudo, pois amplia a pesquisa na área da comunicação não verbal". Ainda, o sujeito adota um conjunto de posturas e atitudes em relação ao espaço que ocupa, isso lhe induz a inferir várias características (FARIAS, 2005). Também, de acordo com Goffman (1971) apud Vasconcelos (2006) as relações entre o ambiente e o comportamento humano demonstram que a configuração espacial dos próprios comportamentos tende a definir-se de modo preciso, segundo regras próprias. A percepção de espaço é dinâmica, em virtude de se encontrar ligada à ação mais do que aquilo que pode ser visto por pura contemplação. Assim, observa-se que os diversos sinais da comunicação não-verbal, principalmente a distância e a postura, possuem uma característica em comum: são elementos espaciais.

Autores afirmam que os sinais espaciais constituem-se como importantes fontes de informação acerca do modo como os indivíduos entram em concordância uns com os outros e com o ambiente na sua totalidade. Com isso, pode-se supor que o tipo de interação está submetido à comunicação utilizada no espaço (HALL, 1977; BITTI, 1997). Sob essa premissa, do comportamento espacial humano no seu ambiente, surge a teoria Proxêmica.

Hall (1977) estruturou um conjunto de informações relacionadas ao comportamento espacial, que tem como proposição a cultura humana. No estudo da comunicação Proxêmica, tal autor destaca que existem quatro distâncias interpessoais, essas são:

1. Distância íntima (zero a $50 \mathrm{~cm}$ ): a essa distância os estímulos sensoriais ficam a mostra; pode ocorrer o contato físico, ocorre a percepção dos odores, do calor humano e os encontros pessoais mais íntimos; a vista fica distorcida por conta da proximidade; a voz é empregada em forma de sussurro.

2. Distância pessoal ( $50 \mathrm{~cm}$ a $1,20 \mathrm{~m}$ ): pode ser descrita como a bolha ou esfera protetiva imaginária que o indivíduo mantém entre si e os demais; nesse caso nem sempre ocorre o contato físico, e a percepção dos odores e do calor do corpo podem não ser sentidos; as dimensões começam a tomar proporção normalizada, dependendo do ponto de distância em que se encontra.

3. Distância social (1,20 m a 3,60 m): é considerado como "o limite da dominação" (HALL, 1977); os detalhes visuais íntimos não são mais possíveis; o nível da voz é normal (importante salientar que o termo normal difere entre culturas, e que o grupo focado neste estudo é o americano); não há mais possibilidade de contato físico, sendo possível apenas o contato visual comum entre os interlocutores; nessa fase, o volume da voz é ligeiramente mais alto, e pode ser ouvido de um cômodo próximo. 
4. Distância pública (acima de 3,60 m): esta fase se situa fora do círculo de envolvimento; detalhes como a cor dos olhos e detalhes corporais não são mais percebidos; a voz necessita de amplificador; é o tipo de distância que acontece em palestras ou atos públicos, portanto, há uma visão coletiva dos interlocutores, e não um contato visual individual.

Vale salientar que o mesmo autor observa que essas distâncias ganham outras dimensões em diferentes culturas, assim como Agnus (2012) também citou a diferença de cultura para cultura. O presente estudo foca o entendimento na cultura norte-americana, fonte primária do autor, como a cultura mais próxima dos sulamericanos, mais especificamente dos brasileiros, pois fazem parte do grupo ocidental.

O termo Proxêmica, cunhado por HALL (1977, p.127) "é usado para definir as teorias e observações interrelacionadas do uso do espaço pelo ser humano". Os conceitos apresentados pelo autor observam as distâncias inconscientemente mantidas por pessoas dentro de certos aspectos, levando em conta a intimidade, o local e contexto em que se encontram e, principalmente, a cultura a que estão submetidos. Bernardinho (2019) defende que a orientação espacial do indivíduo é formada através da relação da percepção corporal e a maneira própria de sentir o espaço.

Diante disso, a intenção deste artigo é observar por meio da Proxêmica o que facilita ou dificulta o convívio social entre os habitantes de um espaço reduzido e confinado, como o veleiro, e, a partir dessas informações, estabelecer sugestões de organização espacial que mais favoreçam o convívio a bordo.

Dentro do espaço que optou por habitar, o indivíduo deve encontrar todas as características que, ao seu ver, o satisfazem física e cognitivamente. "O homem deve ser capaz de orientar-se, de saber onde está. Mas ele também tem de identificar-se com o ambiente, isto é, tem de saber 'como' está em determinado lugar" (NESBITT, 2006, p.443). Essa identificação espacial resulta em segurança emocional do indivíduo e é gerada de maneiras distintas, principalmente definidas por características culturais, como já defendido pelos conceitos da Proxêmica.

O design de ambientes, apoiado nas disciplinas que auxiliam na interpretação do sujeito e na decodificação da realidade contemporânea, pode expressar seus anseios, além do desempenho da sua principal função que é o abrigar. "No coração da cidade, a pessoa precisa de mais espaço em casa, não de menos. A casa deve ser um antídoto para o estresse da cidade" (HALL, 1977, p.157). Os veleiros se tornam moradias principalmente por privilegiarem o espaço exterior, o contato com o natural, como esse antídoto que o autor menciona. Porém, o espaço interno da embarcação pode também proporcionar situação de conforto, quando ambientado de forma a ampliar a qualidade de vida de seus moradores. Quando um indivíduo opta por uma nova moradia, este compreende as adaptações necessárias entre ele e o seu novo lar, de forma recíproca. A habitação explicita informações contidas na formação e cultura do indivíduo. E a materialização das características de apropriação emocional resultará, enfim, em um espaço realmente satisfatório ao seu usuário.

De acordo com o que foi verificado por Silva et al. (2000) os preceitos proxêmicos permitem entender como ocorrem as interações pessoais, na busca de melhor entendimento das formas de relacionamento humano, pois esse processo no qual se compartilham mensagens, ideias e sentimentos podem influenciar o comportamento das pessoas, que o enfrentarão de acordo com suas crenças, valores e história de vida. Manter aproximação sugere maior abertura ou acesso à comunicação, representando maior riqueza na comunicação (HALL, 1977).

De acordo com Stefanelli e Carvalho (2005) para que uma comunicação sensível se manifeste adequadamente, é preciso haver algo que a motive. As emoções e sentimentos interferem na percepção dos sinais emitidos pelo outro, por exemplo, quando tristes, nos voltamos para nós mesmos, percebemos menos o 
outro e nos distanciamos. No entanto, se estamos felizes, ficamos mais próximos, mais receptivos às mensagens do outro.

Hall (1977) discorre que embora o indivíduo não tenha total consciência das distâncias que estabelece entre si e os demais, a variação das distâncias interpessoais está relacionada a aspectos como possibilidade de toque e de sentir calor e odores corporais; conservação de campo visual e auditivo; definição de tom de voz e conteúdo verbalizado; movimentação possível e admissível entre outros fatores intimamente vinculados ao tipo e à qualidade das interações sociais. Importante salientar também que "a maneira das pessoas se sentirem com relação umas às outras, em cada ocasião, é um fator decisivo na distância a ser empregada" (HALL, 1977, p.106).

A integração entre usuário e ambiente deve provocar atitudes no próprio indivíduo que, ao modificar o espaço físico utilizado por ele, pode melhorar as condições de conforto. As características físicas dos elementos como cores, texturas, detalhes de execução, influenciam a percepção e o bem estar do usuário. Elementos que permitem o manuseio como maçanetas de portas e janelas, interruptores, travas e puxadores são importantes para propiciar cooperação entre ocupante e ambiente no controle do conforto. As atitudes, o desempenho e o comportamento do usuário, todos os elementos e o entorno criam o conjunto que determina a conformidade do local e sua função. O papel do usuário no controle do conforto ambiental depende principalmente da possibilidade de intervenção que, por sua vez, está relacionada ao detalhamento dos elementos arquitetônicos. Por exemplo, permitir as trocas de ar através do uso das aberturas quando necessário; prover uma melhor luminosidade, graduando a intensidade de iluminação; controlar o isolamento sonoro dentro do ambiente, através do uso destes elementos; melhorar o conforto do corpo através do uso adequado da própria vestimenta de acordo com o clima e a atividade física que estiver exercendo; modificar a posição do mobiliário para uma melhor visibilidade e, adequar a posição do mobiliário ao corpo. Além das características individuais dos envolvidos e da situação em análise, um fator essencial para a decodificação das relações proxêmicas são os indícios do ambiente sociocultural e físico que possibilitam tais ações. Elali (2009) considerada estudos de Altman (1976) e Lee (1997) e descreve que a noção de privacidade presume um equilíbrio momentâneo ideal entre as propensões do indivíduo se isolar e se tornar acessível aos demais, o que tende a se determinado por normas de convívio social. O autor, ainda com base em Altman (1976) complementa que o desenvolvimento de habilidades para regular as condições de privacidade que a pessoa carece em cada situação está diretamente ligada à autoidentidade e ao reconhecimento dos seus limites no contato com os outros, ou seja, quais "aspectos do ambiente físico e social são partes de si e que aspectos são partes dos outros" (ALTMAN, 1976 apud ELALI (2009, p.25).

Esse governo seletivo de acesso ao eu pode ser cumprido através de algum aspecto do ambiente físico, como ao se possuir um recinto próprio, por exemplo o quarto, casa etc. Na ausência de barreiras físicas evidentes, surgem regras sociais, mais ou menos claras, que ajudam a limitar a intimidade indesejável. Essas normas de defesa da privacidade manifestam-se em nível do comportamento interpessoal ou em nível das relações comportamento ambiente, quando determinado espaço é defendido através da manipulação de objetos ou pela ocupação territorial de lugares especialmente significativos. Assim, conhecer um ambiente significa, entre outras coisas, compreender as funções desse espaço, reconhecendo e aplicando táticas culturalmente adequadas de defesa da privacidade (PINHEIRO e ELALI, 1998 apud ELALI, 2009).

Lidando continuamente com essas regras sociais de uso espacial, as pessoas se tornam capazes de decodificar tal simbologia para regular sua privacidade, e manifestam "personalidades situacionais" (HALL, 1977) derivadas de experiências vivenciadas anteriormente e retomadas de acordo com a circunstância em que se encontram.

Enfim, citando Agnus (2012, p.6) "A maioria das pessoas geralmente desconhece as normas do comportamento proxêmico em sua cultura, mas elas se tornam conscientes delas quando essas normas são 
violadas ou quando percebem diferenças no comportamento espacial". Essas diferenças, ainda segundo o autor, se dão devido ao uso de normas estrangeiras, ou seja, não correspondente a cultura que se aplica. Com as informações coletadas obtidas, parte-se para o estudo de caso, onde, após análise do briefing e do espaço existente, são definidas as alterações de layout utilizando as premissas da Proxêmica como fundamento.

\section{Estudo de caso de veleiro para moradia}

Diante da compreensão do campo de estudo da Proxêmica, realizou-se um estudo de caso em um veleiro reformado para moradia de um casal. O projeto e pesquisa ocorreu entre maio e setembro de 2020. O projeto original da embarcação foi desenhado pelo yacht designer brasileiro Roberto Barros. O modelo é o Multichine36.

Os proprietários atuais da embarcação definiram um briefing básico, solicitaram que o espaço pudesse receber confortavelmente até 6 pessoas. Nesse grupo somam-se um idoso e duas crianças. O casal morador pretende alojar-se no camarote de popa (parte traseira), e o de proa (parte dianteira) ficará para hóspedes. Fora solicitado que este não fosse fechado à área de convívio, mas que se parecesse com uma continuação dele. Assim, a sensação de espaço seria ampliada. Para receber o idoso, a escada deveria receber degraus mais amplos em largura e comprimento, aproveitando a caixa que guarda o motor para tal. Cantos arredondados e apoios no entorno do espaço complementam o suprimento da necessidade. $\mathrm{O}$ acesso a maquinário e espaço exterior é dificultado para as crianças, o que aumenta a segurança para este grupo.

Em relação aos requisitos sensoriais, os proprietários solicitaram linhas limpas, leves e discretas, acabamentos ao mesmo tempo aconchegantes e práticos no sentido da facilidade de limpeza. É importante para estes ampliar visualmente o espaço, e para tornar tangível essa sensação, foram utilizadas cores mais claras nas regiões a partir da linha dos olhos para cima, e mais escuras dessa linha para baixo. O aumento da ventilação cruzada também foi uma solicitação dos usuários. A intenção destes foi criar uma nova configuração de arranjo, já que a anterior os desagradava.

$\mathrm{Na}$ construção, o barco foi executado em aço, e recebeu um motor maior ao dimensionado pelo designer. Isso faz com que a escada que dá acesso ao interior do barco tenha sido redimensionada. A Figura 01 mostra um comparativo entre planta original (a) e planta construída da embarcação (b). 


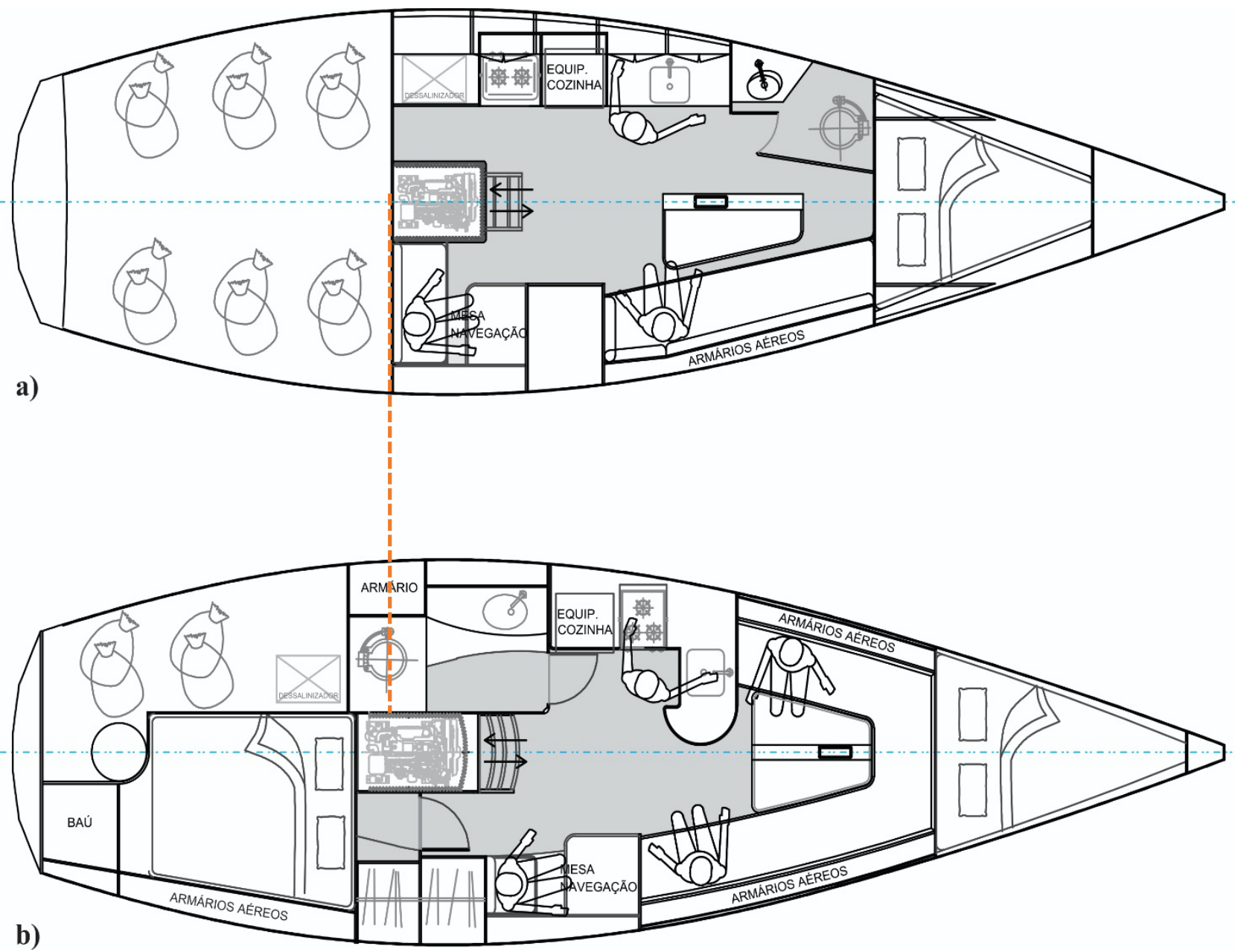

Figura 01: Comparativo entre planta original e planta construída.

Fonte: Autores, 2020.

Além do motor, originalmente o banheiro possuía espaço insuficiente, já que dividia espaço com a parede da cozinha, ambos alocados na parede lateral da embarcação. Não havia praticamente nenhum armário, e não era possível o banho por conta de suas dimensões. Isso foi corrigido modificando a posição, trazendo-o para a região lateral ao motor. Assim, além de aumentar o espaço do banheiro, fora aberta uma área para alocação do sofá, que, com a baixa da mesa, se torna uma cama. A cozinha também recebeu redesenho, sendo reorganizada em "L", possibilitando reduzir ainda mais a ocupação da parede lateral, o que proporcionou o ganho necessário de comprimento para o sofá citado anteriormente. Outro motivo da organização da cozinha em "L", é que assim ocupa-se mais espaço na área central do barco, o que além de equilibrar melhor o peso, aumenta as áreas de pega e apoio durante uma travessia ou um mar revolto.

É importante salientar que se deve respeitar acima de qualquer layout o equilíbrio do barco, evitando aumentar drasticamente seu peso, o que influenciaria na linha d'água e por consequência em vários sistemas da embarcação, e mantendo a distribuição equilibrada do peso entre as duas laterais, e a frente e a parte traseira dele. Como a construção é feita em aço, o peso da estrutura do barco permeia três toneladas, por conta disso a inserção de mobiliário realizada não influenciou no peso geral do barco, e esta também foi distribuída corretamente entre as duas laterais, para evitar o peso excessivo em apenas um dos lados.

No seguinte reajuste do espaço, o barco recebeu um camarote na popa, pois a embarcação que antes realizava longas travessias e necessitava de paióis de carga consideráveis, agora recebe uma família para 
passeios de fim de semana, o que pede um aumento no conforto em detrimento do espaço para carga. $\mathrm{O}$ camarote em questão recebeu duas gaiutas (janelas) para gerar luminosidade natural e ventilação cruzada.

Hall (1977) discorre sobre o espaço de características fixas como sendo o espaço fixo de qualquer espécie, mas que apesar disso, segue um plano que muda com o tempo e a cultura. Porém ao discorrer sobre o espaço de características semifixas, este mesmo autor observa que é possível observar espaços que em uma determinada cultura são considerados fixos, já em outra são semifixos. Como o interior da embarcação oferece um espaço confinado e reduzido, os espaços acabam necessariamente por se tornar multifuncionais, e com essa característica fortalecida podem também ser considerados espaços de características semifixas. A Figura 2 demonstra as principais medidas do espaço da embarcação estudada.

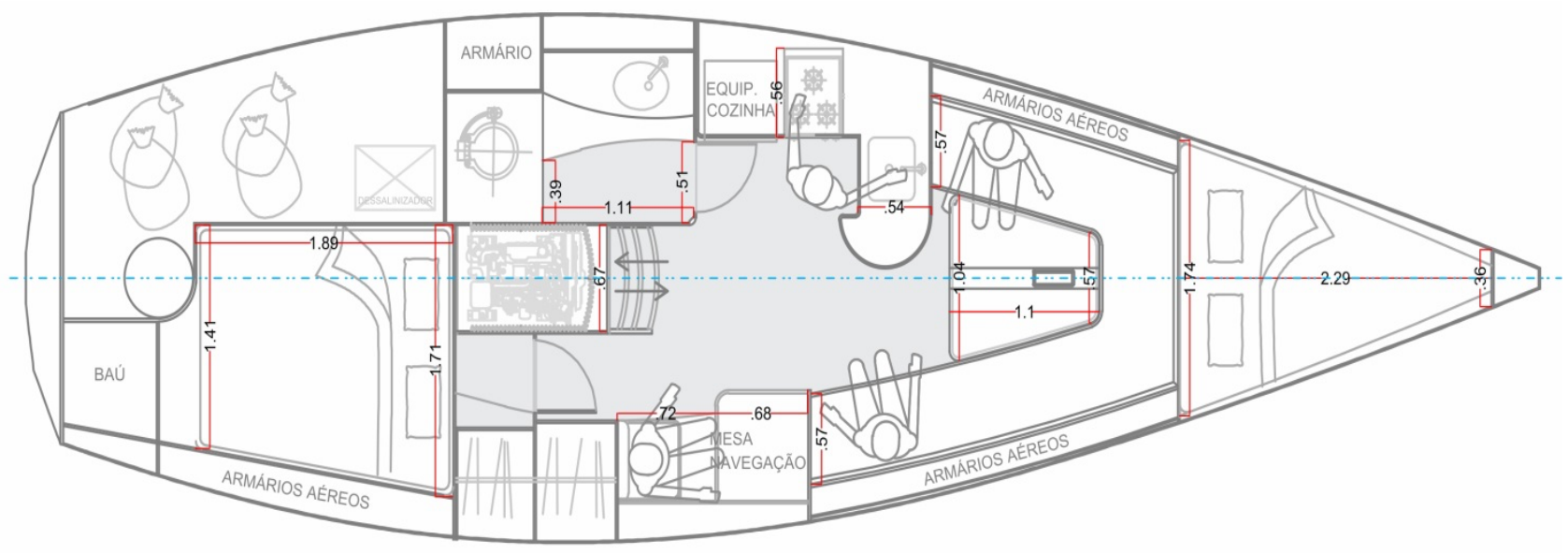

Figura 02: Principais medidas do espaço da embarcação. Fonte: Autores, 2020

Partindo destas características de briefing, foram adotadas a priori as correções necessárias, e com o projeto pré-aprovado em mãos, partiu-se para a observação das manifestações proxêmicas estudadas.

\subsection{Proxêmica e espaço da embarcação}

Por meio da observação Proxêmica, os resultados observados e coletados a partir do novo layout foram divididos em duas categorias de espaços de interlocução (Figura 3), essas são: (a) as respostas entre interlocutores, onde se observa se o ambiente propicia e facilita a interação entre os usuários, e (b) as respostas entre interlocutor e espaço físico, relacionadas com a influência que o ambiente exerce sobre o usuário desse sistema. 


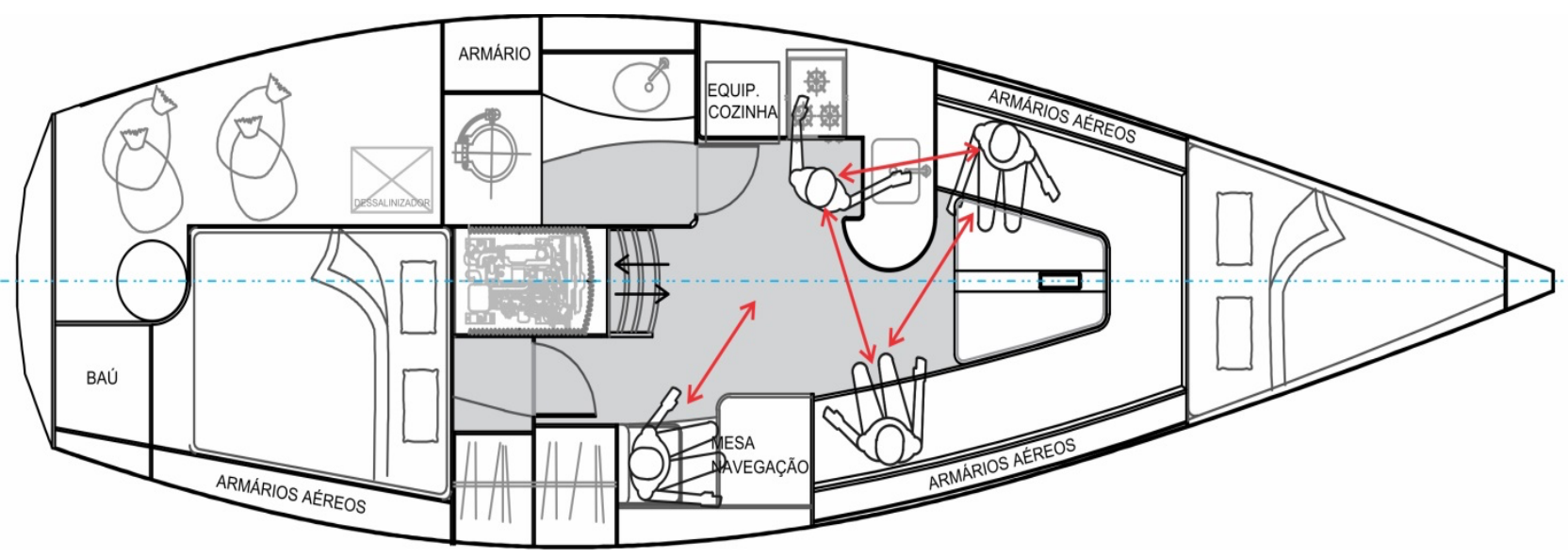

Figura 03: Espaços de interlocução.

Fonte: Autores, 2020.

\subsubsection{Interlocutor X interlocutor}

Como observado pela manifestação Proxêmica, o contato íntimo é estímulo para se fortalecerem laços já existentes. Como os usuários pretendem utilizar o espaço como habitação, e seus convidados em sua maioria serão parentes e amigos íntimos - caso oposto dos charters, veleiros utilizados para passeio por usuários estranhos entre si - aqui observa-se a distância íntima em praticamente todo o perímetro. O distanciamento é um pouco maior apenas para o espaço da mesa de navegação, que é onde o marinheiro precisa concentrar-se para organizar a conduta do trecho que será percorrido. Praticamente todos permanecem sentados, o que para pessoas que não estiverem acostumadas a permanecerem embarcadas se sentem mais seguras, por conta do balanço constante.

O contato com o corpo em posição frontal ao outro interlocutor estimula o interesse à relação. O conceito observado aqui é o sociopeto, caracterizado por Hall (1977) como aglutinador, ou facilitador de interrelações entre indivíduos, contrário do termo sociofugo, que possui características de afastar as pessoas, reduzindo sua interação social. Observa-se na embarcação que é possível intensificar o uso desse artifício.

O contato visual direto também favorece a comunicação seguindo as premissas anteriores. Esse contato é conseguido através da redução de obstáculos visuais, principalmente nos espaços de convívio, como por exemplo, evitando fechamento de paredes entre a cozinha e os sofás. No caso da planta estudada, os únicos ambientes fechados por portas são o banheiro e o camarote do casal morador. Dessa maneira há o favorecimento da socialização geral, sem a perda de privacidade dos usuários.

\subsubsection{Interlocutor X espaço habitado}

A movimentação constante do barco celebra os sentidos em consonância. "Uma das atrações da navegação a vela, segundo muitos entusiastas do esporte, é a interação de experiências visuais, cinestésicas e tácteis" (HALL, 1977, p.64). Evitar a percepção dos sentidos, buscando um ambiente mais inerte é ser contrário à situação em que o indivíduo se propôs a estar nesse momento. Outro ponto considerável é o uso das cores ou texturas diferentes para modificar as sensações espaciais, como por exemplo, utilizando cores escuras no piso e baixa altura, e cores claras em partes altas e no teto, obtendo assim uma sensação de maior amplitude do espaço.

"Nossos espaços urbanos dão pouca excitação ou variação visual e virtualmente nenhuma oportunidade para construir um repertório cinestésico de experiências espaciais." (Hall, 1977, p. 66). O mesmo autor observa a importância da significação das texturas, é necessária a escolha consciente das texturas que serão utilizadas 
no ambiente, a fim de produzir memórias táteis em seus utilizadores. A Figura 4 apresenta a proposta final de layout da embarcação.
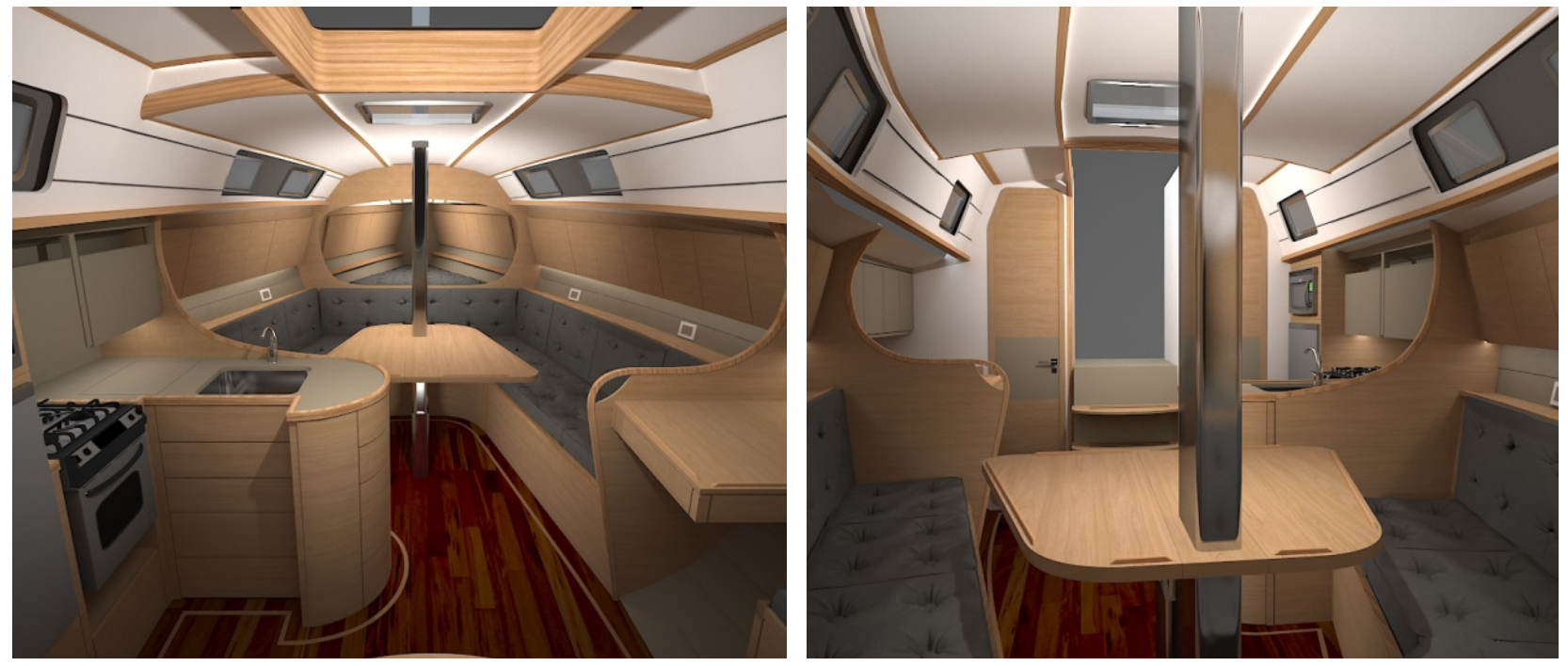

Figura 04: Apresentação da proposta final.

Fonte: Autores, 2020.

Para fortalecer as ideias de contraste, a madeira clara e de cor quente é combinada com os tons de cinza para reduzir a sensação de calor; a madeira possui textura lisa, envernizada, e os tecidos são em veludo, provocando os contrastes também nas texturas. O teto é branco com detalhes em madeira, e também liso e envernizado, dando a sensação de um pé direito mais amplo. Os trechos em madeira no teto são as partes onde há pega-mãos, para que os tripulantes que estejam de pé possam facilmente os visualizem com facilidade e apoiar-se em caso necessário.

A acústica é requisito fundamental na projetação de uma embarcação. A reverberação sonora norteia a posição do indivíduo dentro do espaço. A visão pode ser considerada um sentido incompleto, pois só proporciona real posicionamento do ser no espaço com o auxílio de outros sentidos. No veleiro, por conta do contato direto do barco com a água, esse sentido é percebido de maneira mais natural.

A visão periférica apresenta maior movimentação (HALL, 1977), e isso significa que uma maior quantidade de informação visual na periferia da visão pode causar ao indivíduo maiores sensações de aglomeração. Por conta disso, o uso de objetos decorativos e detalhes contrastantes pode causar sensação de abarrotamento do espaço. Para reduzir a quantidade de informação nessa zona em especial, os armários que permeiam as laterais receberam portas, e sua cor é sempre a mesma em cada ambiente, para que formem apenas uma unidade visual por setor.

As aberturas para o exterior são na linha dos olhos de um adulto de pé. Dessa maneira, a sensação de claustrofobia que possa existir pelo espaço confinado é reduzida.

Hall (1977) retrata que mesmo observando espaços idênticos, o usuário perceberá como mais amplo o ambiente onde os objetos estejam organizados a fim de evitar esbarrões. Na embarcação, a área de giro deve ser mantida livre, para que a sensação de amplitude seja considerada. Não há nenhum tipo de obstáculo na área logo a frente da escada de acesso, toda essa região é deixada livre para facilitar o giro no espaço central da embarcação. O autor completa que a sensação de amplitude depende da possibilidade do indivíduo mover-se com facilidade de um lado para o outro. $\mathrm{Na}$ área da mesa, onde seria mais difícil a passagem até o camarote da proa, a própria mesa recebeu um sistema de descida dos tampos, conhecido por "asas de 
borboleta", dos dois lados do mastro, então, é possível deixar o acesso livre à proa, apenas mantendo os tampos abaixados.

\subsection{Relação das características espaciais aplicadas}

Em observação aos preceitos observados até agora, o Quadro 01 apresenta as características espaciais a serem avaliadas na projetação da embarcação supracitada, e em situações de semelhança com esta.

\begin{tabular}{|c|c|}
\hline INTERLOCUTOR X INTERLOCUTOR & INTERLOCUTOR X ESPAÇO \\
\hline $\begin{array}{ll}\checkmark & \text { Estimular a distância íntima e pessoal } \\
& (0 \text { a } 120 \mathrm{~cm}) \\
\checkmark & \text { Favorecer as posições frontais; } \\
\checkmark & \text { Manter afastada a área de concentração; } \\
\checkmark & \text { Auxiliar a sensação de segurança por conta da } \\
& \text { movimentação constante; } \\
\checkmark & \text { Reduzir obstáculos visuais. }\end{array}$ & 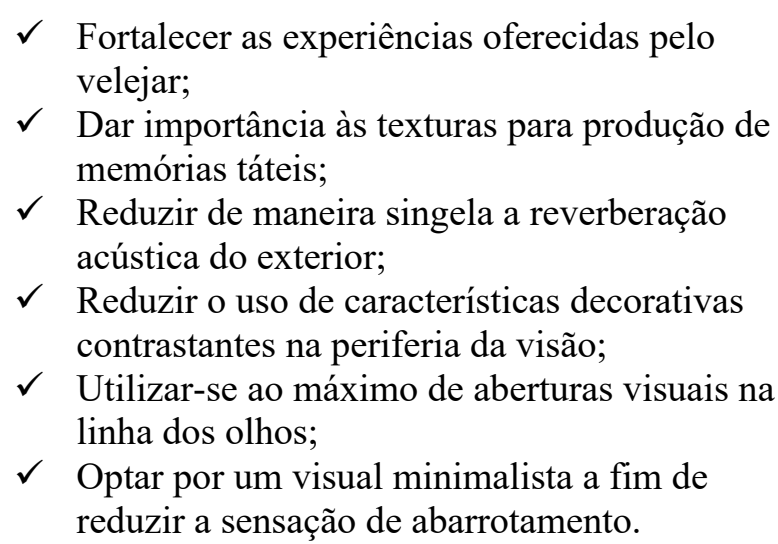 \\
\hline
\end{tabular}

Quadro 01: Apresentação dos dados coletados

Fonte: Autores, 2020

Os princípios ergonômicos observados à luz da Proxêmica apresentam um espaço que, além de favorecer o convívio entre seus utilizadores, se torna também prático e funcional, pois ao mesmo tempo em que trabalham as sensações do usuário, também observam suas considerações físicas e de movimentação dentro desse espaço.

\section{Conclusão}

Avalia-se que os conceitos da teoria Proxêmica aliados às bases sólidas da ergonomia, constituem de um manancial de referência à disposição do designer / projetista, seja ele na área náutica ou em outras finalidades.

Os ambientes hoje buscam cada vez mais alienar os seus utilizadores, ao invés de aumentar suas sensações sensoriais. Isso parte da constante manufatura do espaço habitado. Através das observações das manifestações proxêmicas é possível ampliar essas sensações em um determinado espaço, sem que haja detrimento ao seu conforto, ou ainda, provocando um aumento na sensação deste. A intenção é o aumento do bem estar através da amplificação dos sentidos.

Mediante ao fato do aumento da busca pelo nomadismo, aliado ao momento social em que os trabalhos se tornam mais remotos, a teoria Proxêmica se torna um apoio fundamental na definição de um espaço habitável, seja ele uma residência convencional, ou qualquer outro tipo de formato de moradia, como demonstra o artigo apresentado que observa a habitação em um veleiro. A ergonomia gera a fundamentação dimensional, enquanto que a Proxêmica faz o intermédio entre espaço e usuário de maneira mais assertiva. 
É importante salientar que a pesquisa baseou-se no compilado feito pelo autor Edward Hall focando na cultura norte-americana. Como ainda não há pesquisa satisfatória observando a cultura brasileira de maneira específica, o conteúdo apresentado pode sofrer pequenas divergências culturais a depender da descendência dos indivíduos que utilizarão o espaço. Por conta disso, observa-se uma gama de pesquisas posteriores que possam salientar os detalhes culturais e característicos de cada localidade em questão, pois mesmo no Brasil, observam-se culturas diversas em comparação com suas várias regiões.

\section{Referências}

AGNUS, O. M. Proxemics: the study of space. IRWLE, v. 8, n. 1, p. 1-7, 2012. Disponível em: $<$ https://worldlitonline.net/proxemics-the-o.pdf $>$. Acesso em 29/08/2020.

BERNARDINO JUNIOR, J. C. Um desarranjo brasileiro entre o morar e a habitação. Trabalho de conclusão de curso. Universidade Federal de Santa Catarina, 2019. Disponível em: https://repositorio.ufsc.br/handle/123456789/200650 Acesso em: 20/07/2020.

BITTI, P. R.; ZANI, B. A comunicação como processo social. 2a ed. Lisboa: Estampa, 1997.

CASTRO, Luiz Felipe. Como uma onda: na pandemia, mercado de barcos vive ótima fase. Revista Veja. São Paulo. Ed. $\mathrm{n}^{\mathrm{o}}$ 2726. Disponível em: <https://veja.abril.com.br/economia/como-uma-onda-na-pandemiamercado-de-barcos-vive-otima-fase/> Acesso em: 15/03/2021.

ELALI, G. A. Relações entre comportamento humano e ambiência: uma reflexão com base na psicologia ambiental. UFRN, 2009. Disponível em: https://0501.nccdn.net/4_2/000/000/071/260/Artigo-GLEICEELALI-FULL.pdf Acesso em: 20/07/2020.

FARIAS, L. M. Comunicação proxêmica entre mãe e recém-nascido de risco na unidade neonatal. Dissertação de Mestrado. Universidade Federal do Ceará, 2005. Disponível em: http://livros01.livrosgratis.com.br/cp123628.pdf. Acesso em: 20/07/2020.

HALL, Edward T.. A dimensão oculta. Rio de Janeiro: Francisco Alves, 1977.

NESBITT, K. Fenomenologia do significado e do lugar. In: NESBITT, K. Uma Nova Agenda para a Arquitetura. São Paulo: Cosac Naify, 2006.

SANTOS, R. E. As teorias da comunicação: da fala à internet. SP: Paulinas, 2003.

SILVA, L. M. G.; BRASIL, V. V.; GUIMARÃES, H. C. Q. C. P.; SAVONITTI, B. H. R. A.; SILVA, M. J. $P$. Comunicação não verbal: reflexões acerca da linguagem corporal. Revista Latinoamericana de Enfermagem, Ribeirão Preto, v. 8, n.4, p. 52-58, 2000. Disponível em: https://www.scielo.br/scielo.php?script=sci_arttext\&pid=S0104-11692000000400008 Acesso em: 20/07/2020.

STEFAnelli, M. C.; CARVAlHO, E. C. A comunicação nos diferentes contextos da enfermagem. Barueri: Manole, 2005.

VASCONCELOS, S. G. Comunicação entre mãe-filho em alojamento conjunto à luz dos fatores proxêmicos. Dissertação de mestrado. Universidade Federal do Ceará, 2006. Disponível em: http://repositorio.ufc.br/bitstream/riufc/2028/1/2006_dis_sgvasconcelos.pdf Acesso em: 20/07/2020. 